\title{
Medicamentos como posible factor asociado a la infertilidad masculina
}

\author{
Beatriz Campos Martínez \\ Farmacéutica comunitaria en Alicante.
}

\section{PALABRAS CLAVE}

Fertilidad masculina, espermatogénesis, medicamentos, efectos adversos

\section{ABREVIATURAS}

ACTH: hormona adrenocorticotropa. ADN: ácido desoxirribonucleico. AEMPS: Agencia Española de Medicamentos y Productos Sanitarios. CAT: catalasa.

CIMA: centro de información online de medicamentos de la AEMPS.

CoQ10: coenzima Q10.

CRH: hormona liberadora de corticotrofina.

FMF: fiebre mediterránea familiar.

FSH: hormona folículo estimulante.

FT: ficha técnica.

GSH: glutatión peroxidasa.

HCG: gonadotrofina coriónica humana.

HMG-CoA: hidroximetilglutaril-

coenzima A.

ICSI: inyección intracitoplasmática de esperma.

LDL: lipoproteína de baja densidad.

LH: hormona luteinizante.

LHRH: hormona liberadora de gonadotrofina.

ODV: o-desmetilvenlafaxina.

PA: principio activo.

PEDT: herramienta diagnóstica de la eyaculación prematura.

SNS: Sistema Nacional de Salud.

SOD: superóxido dismutasa.

T3: triyodotironina.

T4: tiroxina.

TBARS: sustancias reactivas al ácido barbitúrico.

TESE: extracción de esperma testicular. TLE: tiempo de latencia eyaculatoria.

TSH: hormona estimulante de la tiroides.

\section{KEYWORDS}

Male fertility, spermatogenesis, pharmaceutical preparations, adverse effects

\section{RESUMEN}

Revisión sistemática de las fichas técnicas (apartados 4.6 y 5.3) de los medicamentos más consumidos en España, según el Sistema Nacional de Salud, y revisión bibliográfica a través de PubMed, según un patrón de búsqueda estándar, con respecto a la influencia de éstos sobre la fertilidad masculina. Como resultado a esto nos encontramos con que de 29 principios activos estudiados, 15 no presentan datos referentes a la fertilidad masculina en su ficha técnica, para 18 no se recuperó información al respecto en la búsqueda en PubMed y 9 no disponen de material de información que provenga de ninguna de las dos fuentes de las que utilizamos. En 3 medicamentos los resultados de las dos fuentes coinciden y en 2 encontramos discrepancias. En 13 de los 29 fármacos estudiados se ha encontrado información de efectos adversos sobre la fertilidad masculina en alguna de las 2 fuentes de información revisadas. Se demuestra con esto una falta de información clara, concisa y contrastada.

\section{Medicines as a possible factor associated with male infertility}

\section{ABSTRACT}

Systematic review of the technical specifications (4.6 and 5.3 paragraph) of the most frequently used drugs in Spain, from NHS, and the information provided by PubMed according to a standard search pattern with respect to their influence on male fertility. As a result of this we find that 15 of 29 active substances studied have no data about male fertility in their technical data sheets, 18 of this 29 have no data about male fertility from PubMed and 9 don't have any information coming from either source we used. 3 medicines have matching results from the two sources and other 2 found discrepancies. In 13 of the 29 drugs studied the information about adverse effects on male fertility was found in one of the two sources of information reviewed. It's demonstrated that it's necessary clear, concise and contrasted information.
Financiación: Ninguna ajerna.

Conflicto de intereses: La autora declara no existir conflicto de intereses en relación con el contenido del artículo.

Cite este artículo como: Campos B. Medicamentos como posible factor asociado a la infertilidad masculina. Farmacéuticos Comunitarios. 2015 Sep 01; 7(3):23-41. doi:10.5672/FC.2173-9218.(2015Nol7).003.05

Correspondencia: Beatriz Campos Martinez (beatrizcamposmartinez112@gmail.com).

ISSN 1885-8619 @SEFAC (Sociedad Española de Farmacia Familiar y Comunitaria). Todos los derechos 


\section{Introducción}

La infertilidad es una enfermedad del sistema reproductivo definida como la incapacidad de lograr un embarazo clínico después de 12 meses o más de relaciones sexuales no protegidas (1). En más del 50\% de las parejas infértiles se halla una capacidad reproductiva masculina deficiente (2), por este motivo esta revisión se va a centrar en los varones.

El factor más común de infertilidad masculina es idiopático, de hecho se da en un $44 \%$ de los varones infértiles (3) aunque hay otras muchas causas como el varicocele, infecciones urogenitales, factores inmunológicos y sexuales, criptorquidia, torsión o traumatismo testicular, disgenesia gonadal y obstrucción de canales reproductores (4). Al mismo tiempo la calidad seminal se ve afectada por múltiples factores, incluso si hubiera fecundación se podría producir un desarrollo anormal y pararse en estadíos avanzados del embrión. Así, haciendo un repaso a la bibliografía existente en las bases de datos encontramos estudios que relacionan parámetros anormales de calidad de semen y/o alteraciones en la fertilidad masculina, con la edad $(5,6)$, peso/IMC $(7)$, ocupación $(5,6)$, disruptores endocrinos (8), drogas (9) y abuso de esteroides (10), entre otros.

Por otro lado, los medicamentos son una de las opciones terapéuticas de primera mano en la atención sanitaria. La población esta sobreexpuesta a ellos, se trata de un problema que combina la falta de adecuación de los tratamientos con el elevado consumo, ya que solo en 2010 el Sistema Nacional de Salud (SNS) facturó 958 millones de recetas (11).

Si tenemos en cuenta la alta prevalencia de infertilidad masculina, con todos los factores que le afectan y con el abuso de medicación en España, es razonable pensar en una revisión acerca de cómo pueden afectar los medicamentos a la calidad del esperma, es decir, ¿son los medicamentos una posible fuente de infertilidad masculina? Un estudio publicado en 2011 asocia el consumo de analgésicos durante el embarazo con el riesgo de criptorquidismo y por lo tanto la posible infertilidad masculina como consecuencia (12), otro estudio habla de una posible azoospermia producida como consecuencia de la toma de colchicina en el tratamiento de fiebre mediterránea familiar (FMF) (13). Además, aunque hay estudios que muestran la posibilidad del tratamiento de azoospermia después de quimioterapia con extracción de esperma testicular-microinyección intracitoplasmática de esperma (TESE-ICSI) hay riesgos genéticos potenciales importantes (14).

Toda esta información motiva este trabajo, el cual se centra en recopilar la información proporcionada por la Agencia Española del Medicamentos y Productos Sanitarios (AEMPS) en sus fichas técnicas con respecto a la fertilidad y complementarla con una revisión para una puesta al día sobre los estudios en curso o recientes que relacionen medicación y fertilidad masculina. El objetivo de este trabajo es realizar una revisión bibliográfica de los medicamentos más utilizados en España como posible fuente de infertilidad masculina, recopilar y clasificar los datos obtenidos para analizarlos y finalmente responder a las preguntas: ¿La ficha técnica del fármaco incorpora información al respecto?, en caso afirmativo, ¿es el medicamento un posible factor asociado a la infertilidad masculina?, ¿puede obtenerse información sobre este problema en PubMed?, ¿hay coincidencia entre la información de ambas fuentes de información?, y ¿qué problemas relacionados con la fertilidad másculina pueden esperarse con estos medicamentos?

\section{Material y métodos}

Se trata de una revisión bibliográfica realizada en los meses mayo-julio de 2014. En primer lugar se accedió al SNS para conocer los subgrupos ATC y principios activos de mayor consumo en España en el año 2010 (revisión más reciente hasta la fecha) (15). A partir de este documento se elaboró una clasificación de los principios activos en función del número de envases utilizados. A continuación se accedió a la página web de la AEMPS en el apartado de "medicamentos de uso humano" y dentro de éste en el Centro de Información online de Medicamentos de la AEMPS (CIMA). Aquí se revisó la ficha técnica de cada uno de los medicamentos aparecidos en la lista elaborada anteriormente. Concretamente se consideró la información aparecida en los apartados 4.6 y 5.3, los cuales hacen referencia a "fertilidad, embarazo y lactancia" y "datos preclínicos sobre seguridad" respectivamente. A partir de los datos, obtenidos se elaboró una tabla en la que se incluian las siguientes entradas: principio activo (PA), fertilidad, fertilidad femenina, fertilidad masculina, embarazo, estudios de fertilidad en animales y estudios de fertilidad en humanos. Se debía anotar exclusivamente si en la ficha técnica se hacía referencia a cada uno de estos datos respondiendo SÍ o NO. Después se analizó la información obtenida, clasificando el principio activo, también de forma dicotómica, en SÍ puede, o NO, afectar a la fertilidad masculina. Se consideró que existía este potencial cuando así se indicó en alguno de los dos apartados estudiados en la ficha técnica, en estudios humanos o animales. Y por último se efectúa un resumen narrativo de la información encontrada al respecto.

Una vez completada la primera parte de la revisión se comenzó con la revisión en las bases de datos. Se usó PubMed, se establecieron dos patrones de búsqueda estándar, así se repitió el mismo procedimiento con todos y cada uno de los medicamentos de la lista. El procedimiento dentro de PubMed fue el siguiente:

1. Se accedió a la web: http://www. ncbi.nlm.nih.gov/pubmed/

2. Se seleccionó MeSH en el desplegable y se introdujo "male fertility" en la barra (1 ${ }^{\text {a }}$ búsqueda).

3. Se seleccionaron los 4 resultados que aparecen y se añadieron a "PubMed search builder" con el nexo "OR".

4. Se cambió el nexo a "AND” y añadimos el principio activo de interés.

Se añadió el grupo terapéutico en la búsqueda y todos los principios activos aparecidos en la lista que estuvieran dentro de este grupo, de esta manera la búsqueda era más directa y se recogía más información en un solo paso. Se siguió el orden establecido en la tabla 1, es decir, se empezó con omeprazol, así se seleccionaron todos los principios activos que están en el mismo grupo terapéutico que él y aparecen en el listado, y se comenzó la búsqueda. Ejemplo:

AND ("Omeprazole" [Mesh] OR "pantoprazole" [Supplementary Concept] OR "Proton Pump Inhibitors" [Mesh] OR "Proton Pump Inhibitors" [Pharmacological Action] OR "Proton Pumps" 
[Mesh]).Por último se añadieron filtros, en este caso el filtro fue "clinical trials”. Ejemplo final de la búsqueda:

("Fertility Agents, Male" [Mesh] OR "Infertility, Male" [Mesh] OR "Contraception" [Mesh] OR "Fertility Agents, Male" [Pharmacological Action]) AND ("Omeprazole" [Mesh] OR "pantoprazole" [Supplementary Concept] OR "Lansoprazole"[Mesh] OR "Esomeprazole/adverse effects" [Mesh] OR "Esomeprazole/pharmacology" [Mesh] OR "Esomeprazole/ therapeutic use" [Mesh] OR "Proton Pump Inhibitors" [Mesh] OR "Proton Pump Inhibitors" [Pharmacological Action]).

En todas las búsquedas se accedió a "related citations" aunque siempre se le dio prioridad al resultado inicial.

En la segunda búsqueda se escribió "SPERM" en MeSH, de los resultados obtenidos se seleccionaron siempre los siguientes: spermatozoa, spermatocytes, spermatogenesis, spermatogenesis-blocking agents, sperm motility y sperm maturation. Se añadió sólo el grupo terapéutico con el nexo AND. Ejemplo:

("Spermatozoa"[Mesh] OR "Spermatocytes" [Mesh] OR "Spermatogenesis" [Mesh] OR "Spermatogenesis-Blocking Agents" [Mesh] OR "Sperm Motility" [Mesh] OR "Sperm Maturation" [Mesh]) AND ("Proton Pump Inhibitors" [Mesh] OR "Proton Pump Inhibitors" [Pharmacological Action]) AND (hasabstract[text] AND "humans" [MeSH Terms]).

En algunos principios activos y grupos terapéuticos se alteró el patrón de búsqueda. Todo ello está registrado y explicado en los resultados.

Con los resultados de cada búsqueda se elaboró una tabla que incluía las siguientes entradas: grupo terapéutico, PA, título del artículo (en inglés, como aparece en PubMed), tipo estudio (tal como lo definen sus autores), año, accesibilidad en PubMed (solo título, resumen, o texto completo libre), especie (si se trata de estudio en humanos o en animales, y en qué tipo de animal) y específico (se clasificó como tal el estudio específicamente diseñado para evaluar la influencia del fármaco sobre la capacidad reproductiva, e inespecífico si el estudio tenía otra finalidad, pero de la información obtenida sus autores inferían riesgos reproductivos). Posteriormente se comentó cada uno de los estudios mencionados en las tablas.
Tabla 1. Los 35 principios activos más consumidos en España en orden de $n^{\circ}$ de envases dispensados (miles de unidades) en el año 2010

\begin{tabular}{|c|c|c|}
\hline PA & $\mathrm{n}^{\circ}$ envases & ATC \\
\hline Omeprazol & $51.874,63$ & $\mathrm{~A} 02 \mathrm{BC} 01$ \\
\hline Paracetamol & $34.312,94$ & N02BE01 \\
\hline Ibuprofeno & $23.498,97$ & M01AE01 \\
\hline Atorvastatina & $16.388,28$ & C10AA05 \\
\hline Pantoprazol & $7.020,19$ & A02BC02 \\
\hline Tamsulosina & $6.033,85$ & G04CA02 \\
\hline Escitalopram & $5.606,65$ & N06AB 10 \\
\hline Salmeterol asociado & $4.977,16$ & R03AK06 \\
\hline Clopidogrel & $4.943,08$ & B01AC04 \\
\hline Lansoprazol & $4.901,54$ & $\mathrm{~A} 02 \mathrm{BCO} 3$ \\
\hline Valsartán y diuréticos & $4.746,32$ & CO9DA03 \\
\hline Valsartan & $4.417,45$ & C09CA03 \\
\hline Tiotropio bromuro & $3.770,99$ & R03BB04 \\
\hline Risedrónico ácido & $3.610,87$ & M05BA07 \\
\hline Venlafaxina & $3.446,48$ & N06AX16 \\
\hline Citicolina & $3.420,96$ & N06BX06 \\
\hline Formoterol asociado & $3.406,35$ & R03AK07 \\
\hline Candesartán & $3.248,95$ & C09CA06 \\
\hline Esomeprazol & $3.165,89$ & A02BC05 \\
\hline Pregabalina & $2.959,67$ & N03AX16 \\
\hline Irbesartán y diuréticos & $2.804,64$ & CO9DA04 \\
\hline Montelukast & $2.722,78$ & R03DC03 \\
\hline Duloxetina & $2.473,01$ & N06AX21 \\
\hline Ácido lbandrónico & $2.373,99$ & M05BA06 \\
\hline Fentanilo & $2.264,96$ & N01AH01 \\
\hline Risperidona & $2.092,2$ & N05AX08 \\
\hline Ezetimiba & $2.088,4$ & C10AX09 \\
\hline Insulina Glargina & $1.961,89$ & A10AE04 \\
\hline Enoxaparina & $1.827,13$ & B01AB05 \\
\hline Quetiapina & $1.768,01$ & $\mathrm{~N} 05 \mathrm{AH} 04$ \\
\hline Olanzapina & $1.379,18$ & N05AH03 \\
\hline Levetiracetam & $1.054,2$ & N03AX 14 \\
\hline Donepezilo & 851,79 & N06DA02 \\
\hline Rivastigmina & 540,02 & N06DA03 \\
\hline Memantina & 454,05 & N06DX01 \\
\hline
\end{tabular}

PA: principio activo; ATC: clasificación anátomo-terapéutica-química. 
Con el fin de simplificar la revisión y ajustarla a la disponibilidad de tiempo/espacio, se excluyeron algunos medicamentos de la lista. Se optó por excluir a todos aquellos que incluían más de un principio activo como por ejemplo: salmeterol asociado. También a los utilizados para el tratamiento de la demencia, ya que se consideró que no tendrían ninguna relevancia los resultados.

\section{Resultados}

En la tabla 1 se recoge la lista de los 35 principios activos más consumidos en España en orden de $n^{\circ}$ de envases dispensados (miles de unidades) en el año 2010. Se puede decir que el 20\% son medicamentos que afectan al sistema nervioso. Concretamente se trata de fármacos psicoanalépticos entre los cuales encontramos en nuestra lista antidepresivos, psicoestimulantes y nootrópicos, y fármacos contra la demencia. Con un 11,4\% de presencia en nuestra lista se encuentran medicamentos que afectan al aparato digestivo, sistema respiratorio y sistema cardiovascular. Los del aparato digestivo pertenecen todos al grupo de inhibidores de la bomba de protones, en cuanto al sistema respiratorio los más consumidos son los agentes contra padecimientos obstructivos de las vías respiratorias y con respecto al sistema cardiovascular se encuentran en la lista los antagonistas de angiotensina II (antihipertensivos).

La información que proporciona la tabla 2 exclusivamente dice si la fertilidad se nombra en las fichas técnicas proporcionadas por la AEMPS y, si es así, si se mencionan estudios realizados para basar la información proporcionada. En esta tabla se observa que sólo en el caso de pregabalina se nombra algún estudio de fertilidad realizado en humanos, siendo ésta el único principio activo que responde SÍ a todas las cuestiones de la tabla. Hay un 51,4\% de los casos que mencionan la existencia de estudios de fertilidad realizados con animales. Solamente en el caso de tamsulosina no se habla de embarazo, lo cual tiene lógica ya que es un medicamento usado en hombres, aunque hay que destacar que es el único principio activo que responde NO a todas las cuestiones de la tabla. La fertilidad masculina, que es el tema que nos ocupa, aparece en el $34,3 \%$ de los casos frente a un 37,1\% de nombramiento de fertilidad femenina. En cuanto a la mención de la fertilidad sin especificar si femenina o masculina, lo vemos en el 62,9\% de los casos.

A continuación se hace un breve resumen de la información extraída de los puntos 4.6 y 5.3 de la ficha técnica de cada uno de los principios activos aparecidos en la tabla, centrándolo en los datos aportados sobre fertilidad masculina.

\section{Omeprazol}

No se hace mención de cómo puede afectar este fármaco a la fertilidad masculina y no solo eso, sino que tampoco se nombra la fertilidad en términos generales, sin aportar información de ningún estudio realizado que pueda orientar sobre los efectos a nivel reproductivo. Sí que se nombra el embarazo hablando de tres estudios que no muestran reacciones adversas sobre el embarazo y por lo tanto haciendo al omeprazol un medicamento seguro para su uso durante el periodo de gestación.

\section{Paracetamol}

Su ficha técnica habla de estudios de toxicidad crónica en animales que demuestran que dosis elevadas de este principio activo producen atrofia testicular e inhibición de la espermatogénesis, aunque apunta que se desconoce la importancia de este hecho para su uso en humanos. En cuanto al embarazo, no se describen problemas por lo que puede considerarse un medicamento seguro.

\section{Ibuprofeno}

No hay mención a la fertilidad masculina, pero sí habla de una alteración en la fertilidad femenina contraindicando el uso para las mujeres que están intentando concebir. No se mencionan estudios de fertilidad realizados. En cuanto al embarazo, está contraindicado su uso en el tercer trimestre.

\section{Atorvastatina}

Apunta que no hay efectos del principio activo sobre la fertilidad tanto masculina como femenina ba- sándose en estudios con ratas, conejos y perros. Contraindica el uso durante el embarazo de forma rotunda.

\section{Pantoprazol}

Ligera mención a la fertilidad sin especificar en sexos, diciendo que las investigaciones no revelan evidencias de alteraciones en la fertilidad. No incluye ningún estudio de fertilidad pero sí nombra estudios de reproducción que muestran fetotoxicidad. No recomienda el uso durante el periodo de gestación a menos que sea claramente necesario.

\section{Tamsulosina}

$\mathrm{Su}$ ficha técnica no habla de la fertilidad como tal. No nombra estudios de fertilidad y en cuanto al embarazo éste no aparece ya que es una medicación no indicada para su uso en mujeres.

\section{Escitalopram}

Los datos ofrecidos por la ficha técnica están extrapolados de la información de citalopram. No se observa ningún impacto en la fertilidad en humanos, pero habla de estudios en animales que apuntan a una alteración en la calidad del esperma y puntualiza el efecto como reversible en las notificaciones de casos en humanos.

En el apartado 5.3 (datos preclínicos sobre seguridad) se dice que los datos en animales han mostrado una reducción de la fertilidad, del número de implantaciones y esperma anormal, añade que no hay datos disponibles en animales con escitalopram. El uso durante el embarazo debe ser sólo bajo una cuidadosa evaluación del beneficio/riesgo.

\section{Salmeterol asociado}

Los estudios en animales no muestran efectos en la fertilidad. No hay distinción entre sexos. Se recomienda el uso durante el embarazo si el beneficio/riesgo es positivo y siempre a dosis mínimas eficaces.

\section{Clopidogrel}

Se ha observado que el fármaco no ejerce ningún efecto sobre la fertilidad de las ratas machos y hembras. 
Tabla 2. Fertilidad mencionada o no en las fichas técnicas de la AEMPS y estudios nombrados

\begin{tabular}{|c|c|c|c|c|c|c|}
\hline PA & Fertilidad & F. Fem. & F. masc. & Embarazo & $\begin{array}{l}\text { Estudios } \\
\text { fertilidad } \\
\text { animales }\end{array}$ & $\begin{array}{l}\text { Estudios } \\
\text { fertilidad } \\
\text { humanos }\end{array}$ \\
\hline Omeprazol & No & No & No & Si & No & No \\
\hline Paracetamol & Si & No & Sí & Si & Sí & No \\
\hline Ibuprofeno & Si & Si & No & Si & No & No \\
\hline Atorvastatina & Sí & Si & Si & Sí & Sí & No \\
\hline Pantoprazol & Si & No & No & Si & No & No \\
\hline Tamsulosina & No & No & No & No & No & No \\
\hline Escitalopram & Si & Si & Sí & Si & Si & No \\
\hline Salmeterol asociado & Si & No & No & Si & Si & No \\
\hline Clopidogrel & Si & Si & Si & Sí & Si & No \\
\hline Lansoprazol & No & No & No & Sí & No & No \\
\hline Valsartán y diuréticos & No & No & No & Si & No & No \\
\hline Valsartán & Sí & Sí & Si & Si & Si & No \\
\hline Tiotropio bromuro & Si & No & No & Si & Si & No \\
\hline Risedrónico ácido & No & No & No & Si & No & No \\
\hline Venlafaxina & Si & Si & Si & Si & Si & No \\
\hline Citicolina & No & No & No & Sí & No & No \\
\hline Formoterol asociado & Sí & Si & No & Si & No & No \\
\hline Candesartán & No & No & No & Sí & No & No \\
\hline Esomeprazol & No & No & No & Sí & No & No \\
\hline Pregabalina & Si & Si & Si & Si & Sí & Si \\
\hline Irbesartán y diuréticos & Si & Si & Si & Si & Si & No \\
\hline Montelukast & Si & No & No & Si & Si & No \\
\hline Duloxetina & Si & Si & Si & Si & No & No \\
\hline Ácido ibandrónico & No & No & No & Si & No & No \\
\hline Fentanilo & Si & No & No & Sí & Sí & No \\
\hline Risperidona & No & No & No & Si & No & No \\
\hline Ezetimiba & Si & Si & Si & Si & Sí & No \\
\hline Insulina glargina & Si & No & No & Si & Sí & No \\
\hline Enoxaparina & Si & Si & Si & Si & Si & No \\
\hline Quetiapina & No & No & No & Si & No & No \\
\hline Olanzapina & No & No & No & Sí & No & No \\
\hline Levetiracetam & Si & Si & Si & Si & Si & No \\
\hline Donepezilo & Si & No & No & Si & Sí & No \\
\hline Rivastigmina & Si & No & No & Si & Si & No \\
\hline Memantina & No & No & No & Si & No & No \\
\hline
\end{tabular}

Fertilidad: En la ficha técnica hay información general sobre fertilidad; F Fem: Hay o no información e la ficha técnica sobre fertilidad femenina; F Masc: Hay o no información sobre fertilidad masculina en ficha técnica; Embarazo: Se hace referencia al embarazo en la ficha técnica; Estudios fertilidad animales: Se refieren, o no, estudios de fertilidad en animales en la ficha técnica; Estudios fertilidad humanos: Aparecen, o no, estudios de fertilidad en humanos en la ficha técnica. 
Debido a la falta de datos clínicos recomienda no hacer uso del principio activo durante el periodo de gestación.

\section{Lansoprazol}

No hay mención a la fertilidad en ningún aspecto $\mathrm{y}$ se desaconseja el uso durante el embarazo. No se nombran estudios de fertilidad realizados.

\section{Valsartán y diuréticos}

No hay información sobre la fertilidad ni se mencionan estudios de fertilidad realizados. En cuanto al embarazo, está desaconsejado su uso durante el primer trimestre y contraindicado durante el segundo y tercero.

\section{Tiotropio bromuro}

No hay datos clínicos sobre la fertilidad. Se menciona un estudio general sobre reproducción y fertilidad en ratas en el que no se observó ningún efecto adverso en la fertilidad o la conducta de apareamiento. No se especifican los sexos. En cuanto al embarazo, no se disponen de datos clínicos por lo que se recomienda el uso cuando esté claramente indicado.

\section{Ácido risedrónico}

En la ficha técnica habla de toxicidad testicular con dosis excesivas sobre las terapéuticas en ratas y perros. No hay datos suficientes del uso en mujeres embarazadas por lo que no está aconsejado el uso durante el periodo de gestación.

\section{Venlafaxina}

Refiere un estudio realizado en ratas machos y hembras, con dosis superiores a las usadas en humanos, del metabolito activo, o-desmetilvenlafaxina (ODV) en el que se observó una reducción de la fertilidad, pero puntualiza que se desconoce la relevancia en seres humanos. En el embarazo no hay datos suficientes y se recomienda considerar el beneficio/ riesgo.

\section{Citicolina}

No se nombra la fertilidad en ningún aspecto ni se mencionan estudios de fertilidad realizados. Solo debe usarse en el embarazo en el caso de que el beneficio terapéutico supere el riesgo.

\section{Formoterol asociado}

No se menciona la fertilidad masculina. La ficha técnica hace referencia a estudios de reproducción en ratas que mostraron fertilidad reducida en hembras. No recomienda el uso durante el embarazo en especial en la fase previa al parto.

\section{Candesartán}

No aparece información relativa a la fertilidad masculina o femenina ni estudios de fertilidad realizados. Desaconseja la toma del medicamento durante el primer trimestre y está contraindicado durante el segundo y tercero.

\section{Esomeprazol}

No se nombra la fertilidad en ningún momento ni aspecto. En cuanto al embarazo, los datos clínicos son insuficientes y se recomienda precaución en la prescripción del fármaco.

\section{Pregabalina}

Aparece mencionado un ensayo clínico que evalúa el efecto del principio activo sobre la movilidad de los espermatozoides en varones. El resultado es negativo. Además se añade que estudios de fertilidad en ratas macho han mostrado efectos adversos sobre la reproducción. Los efectos adversos sobre el esperma fueron reversibles y se puntualiza que se encontraron efectos adversos sobre fertilidad en ratas macho y hembras a dosis por encima de la terapéutica. Especifica que estos resultados se consideraron de pequeña o nula relevancia clínica. En cuanto al embarazo no recomienda el uso en periodo de gestación.

\section{Irbesartán y diuréticos}

Anota que en la asociación irbesartán/hidroclorotiazida los efectos no han sido evaluados en estudios en animales ya que en monoterapia no hay evidencia de efectos adversos. En periodo de gestación no se recomienda en el primer trimestre y se contraindica durante el segundo y tercero.

\section{Montelukast}

Menciona estudios en animales que mostraron no influencia del principio activo en la fertilidad. No distingue entre machos y hembras. En cuanto al embarazo solo se permite el uso del medicamento si se considera claramente necesario.

\section{Duloxetina}

En la ficha técnica aparece que el fármaco no tuvo efecto sobre la fertilidad masculina y los efectos en mujeres solo fueron evidentes en dosis que causaron toxicidad materna. No menciona si hubo estudios en animales o humanos. En cuanto al embarazo aconseja el uso solamente si el beneficio potencial supera el riesgo potencial para el feto.

\section{Ácido ibandrónico}

No menciona la fertilidad masculina. En cuanto a la femenina hace referencia a resultados del tratamiento oral de ratas y conejos y dice haber un descenso del número de lugares de implantación. No se debe usar en el embarazo ya que no hay datos suficientes acerca del uso en mujeres embarazadas.

\section{Fentanilo}

En un estudio de fertilidad en ratas se observó un efecto asociado a los machos a altas dosis (consistente con los efectos sedantes de fentanilo) aunque no especifica qué tipo de efecto. No debe usarse en el embarazo a menos que sea estrictamente necesario.

\section{Risperidona}

No menciona la fertilidad, ni masculina ni femenina. Apunta que en estudios se han observado efectos adversos en el comportamiento de los padres durante el apareamiento. Se desaprueba el uso en embarazo excepto si fuera claramente necesario.

\section{Ezetimiba}

No hay ensayos clínicos sobre el efecto del principio activo en la fertilidad en humanos pero sí en animales. Dice no tener efectos sobre la fertilidad de ratas macho y hembra. Se contraindica el uso durante el embarazo. 
Insulina glargina

Comenta que los estudios en animales no indican efectos perjudiciales directos en términos de fertilidad. No especifica en machos o hembras. En cuanto al embarazo se puede considerar su uso cuando esté clínicamente indicado.

\section{Enoxaparina}

El fármaco no mostró tener efectos sobre la fertilidad de ratas machos o hembras con dosis de hasta $20 \mathrm{mg} /$ $\mathrm{Kg} /$ día. Sólo debe usarse en el periodo de gestación cuando el médico establezca una clara necesidad.

\section{Quetiapina}

No se menciona la fertilidad en ningún aspecto ni se habla de machos o hembras en estos términos. No se ha establecido la seguridad durante el embarazo humano por lo que solo deberá utilizarse si los beneficios justifican los riesgos potenciales.

\section{Levetiracetam}

No se observó ningún efecto adverso sobre la fertilidad de ratas machos o hembras a dosis de hasta 6 veces la máxima recomendada. No se recomienda el uso en el embarazo a menos que sea clínicamente necesario.

\section{Donepezilo}

El fármaco no mostró efectos sobre la fertilidad de ratas, no distingue entre sexos. En cuanto al embarazo habla de que no debe usarse salvo que sea estrictamente necesario.

\section{Rivastigmina}

Dice no observarse efectos sobre la fertilidad de ratas y conejos sin especificar si hembras o machos, aunque advierte de la excepción con dosis que inducen toxicidad materna sin aporte de datos concretos. Para el embarazo se recomienda el no uso a menos que fuera estrictamente necesario, ya que no se disponen de datos clínicos.

\section{Memantina}

No se hace mención a la fertilidad ni masculina ni femenina. En cuanto al periodo de gestación dice que no debe utilizarse excepto que sea claramente necesario ya que no se disponen de datos clínicos.
A continuación se presentan los resultados de las búsquedas en PubMed.

\section{Omeprazol-pantoprazol-}

lansoprazol-esomeprazol/ inhibidores de la bomba de protones A02

En la tabla 3 se recogen los resultados de la búsqueda en PubMed.

La espermatogénesis está principalmente controlada por la acción endocrina de la hormona folículo estimulante (FSH) y la paracrina de la testosterona sobre las células de Sertoli, además la LH inicia la biosintesis de la testosterona y niveles bajos de hormonas tiroideas pueden ser causa de esterilidad masculina. El primer estudio mencionado (16) incluyó 8 sujetos sanos a los que se les administró $60 \mathrm{mg}$ de omeprazol frente a placebo durante 1 semana. En día 7 se midieron concentraciones basales de FSH, LH, prolactina, testosterona, $\mathrm{TSH}$, tiroxina (T4) y triyodotironina (T3), también gonadotropinas en respuesta a LHRH y prolactina y TSH en respuesta a TRH. El resultado fue que no hubo diferencias de valores basales y estimulados entre omeprazol y placebo.

Tabla 3. Estudios que relacionan los IBP con la fertilidad, recuperados a partir de la primera búsqueda en PubMed

\begin{tabular}{|c|c|c|c|c|c|c|c|}
\hline $\begin{array}{c}\text { Grupo } \\
\text { terapéutico }\end{array}$ & Principio activo & Título & $\begin{array}{l}\text { Tipo de } \\
\text { estudio }\end{array}$ & Año & Accesible & Especie & Especifico* \\
\hline \multirow{4}{*}{$\begin{array}{l}\text { Inhibidores de la } \\
\text { bomba de protones }\end{array}$} & Omeprazol & $\begin{array}{l}\text { The effects of } \\
\text { omeprazole on } \\
\text { endocrine function } \\
\text { in man. (16) }\end{array}$ & $\begin{array}{c}\text { Estudio } \\
\text { aleatorio } \\
\text { cruzado, } \\
\text { doble ciego }\end{array}$ & 1987 & Resumen & Humanos & No \\
\hline & Pantoprazol & $\begin{array}{c}\text { Effects of } \\
\text { pantoprazole on } \\
\text { endocrine function } \\
\text { in healthy male } \\
\text { volunteers. (17) }\end{array}$ & $\begin{array}{l}\text { Estudio } \\
\text { aleatorio, } \\
\text { cruzado } \\
\text { múltiple, } \\
\text { doble ciego }\end{array}$ & 1994 & Resumen & Humanos & No \\
\hline & Lansoprazol & $\begin{array}{l}\text { The effects of } \\
\text { lansoprazole, } 30 \\
\text { or } 60 \mathrm{mg} \text { daily, on } \\
\text { intragastric } \mathrm{pH} \\
\text { and on endocrine } \\
\text { function in healthy } \\
\text { volunteers. (18) }\end{array}$ & $\begin{array}{l}\text { Estudio } \\
\text { aleatorio, } \\
\text { cruzado } \\
\text { múltiple, } \\
\text { doble ciego }\end{array}$ & 1993 & Resumen & Humanos & No \\
\hline & Esomeprazol & $x$ & $x$ & $x$ & $x$ & $x$ & $x$ \\
\hline
\end{tabular}

* Específicamente dirigido a la capacidad reproductora.

$X: \sin$ datos. 
Tabla 4. Resultados obtenidos a partir de la segunda búsqueda a través de PubMed. Relación entre IBP y fertilidad masculina

\begin{tabular}{|c|c|c|c|c|c|c|}
\hline $\begin{array}{c}\text { Grupo } \\
\text { terapéutico }\end{array}$ & Título & Tipo de estudio & Idioma & Año & Especie & Especifico* \\
\hline $\begin{array}{c}\text { Inhibidores de } \\
\text { la bomba de } \\
\text { protones }\end{array}$ & $\begin{array}{l}\text { Induction of aneuploidy } \\
\text { in male mouse germ cells } \\
\text { detected by the sperm-FISH } \\
\text { assay: a review of the present } \\
\text { data base. (19) }\end{array}$ & Revisión & Inglés & 2002 & $\begin{array}{l}\text { Animales } \\
\text { (ratones) }\end{array}$ & Sí \\
\hline
\end{tabular}

* Específicamente dirigido a la capacidad reproductora.

El segundo estudio (17) se llevó a cabo en 12 voluntarios varones durante 2 semanas. Se les administró 40 mg de pantoprazol frente a placebo. El resultado fue que pantoprazol no influyó en niveles plasmáticos de testosterona, cortisol circadiano y niveles plasmáticos de cortisol después de una estimulación exógena con ACTH comparando con el placebo.

En el tercer estudio (18) se incluyen 12 voluntarios masculinos sanos a los que se les administró de 30 a $60 \mathrm{mg}$ de principio activo durante 7 días frente a placebo. Se midieron insulina, aldosterona, testosterona, parathormona, glucagón, T3, T4, TSH, LH, FSH, STH, prolactina, perfil de cortisol circadiano y ACTH test. Se concluyó que no había una influencia clínicamente relevante sobre la función endocrina.

No se obtuvieron resultados sobre esomeprazol.
La tabla 4 recoge los resultados obtenidos a partir de la segunda búsqueda en PubMed. Se trata de un estudio (19) acerca de las aneuploidías inducidas por sustancias químicas y como prueba genética se empleó el FISH con sondas para cromosomas 8 , $\mathrm{X}$ e Y. Se les administró 10 principios activos entre los que se encontraba omeprazol y el resultado fue que no indujo disomías o diploidías a las dosis utilizadas.

\section{Paracetamol/anilidas}

Como resultado de la primera búsqueda aparecieron 7 artículos de los cuales ninguno era de interés para esta revisión. No relacionaban el paracetamol con la fertilidad masculina. En la segunda búsqueda se recogió un artículo no relacionado por lo que se eliminaron los filtros y aparecieron 74 resultados. Se buscaron aquellos que incluyeran en el título la palabra paracetamol.

La tabla 5 recoge 3 estudios que relacionan el paracetamol con la fertilidad masculina. En el primer estudio (20) se trataron ratas macho durante 30 días con dosis de paracetamol de 500 y $1.000 \mathrm{mg} / \mathrm{Kg}$. Se evaluaron el comportamiento sexual y la fertilidad. Así se concluyó que en el día 30 había una disminución de la líbido y se redujeron significativamente los índices de implantación y fertilidad resultantes de la oligozoospermia y deficiencia de la motilidad del esperma.

En el segundo estudio (21) se administraron diariamente dosis altas de paracetamol $(500 \mathrm{mg} / \mathrm{kg})$ a ratas macho. El resultado fue que durante la espermatogénesis se produjo una disminución significativa del peso de los testículos, un aumento de la actividad de la glutatión transferasa en el citosol y de peróxidos de lípidos en

Tabla 5. Relación entre el paracetamol y la fertilidad masculina. Segunda búsqueda en PubMed

\begin{tabular}{|c|c|c|c|c|c|c|c|}
\hline $\begin{array}{c}\text { Grupo } \\
\text { terapéutico }\end{array}$ & Principio activo & Título & $\begin{array}{l}\text { Tipo } \\
\text { estudio }\end{array}$ & Año & Accesible & Especie & Especifico* \\
\hline \multirow{3}{*}{ Anilidas } & \multirow{3}{*}{ Paracetamol } & $\begin{array}{l}\text { Long-term } \\
\text { administration } \\
\text { of large doses of } \\
\text { paracetamol impairs } \\
\text { the reproductive } \\
\text { competence of male } \\
\text { rats. }(20)\end{array}$ & $X$ & 2000 & $\begin{array}{c}\text { Texto } \\
\text { completo }\end{array}$ & $\begin{array}{c}\text { Animales } \\
\text { (ratas) }\end{array}$ & Sí \\
\hline & & $\begin{array}{l}\text { Effect of daily high } \\
\text { doses of paracetamol } \\
\text { given orally during } \\
\text { spermatogenesis in } \\
\text { the rat testes. (21) }\end{array}$ & $X$ & 1984 & Resumen & $\begin{array}{c}\text { Animales } \\
\text { (ratas) }\end{array}$ & Sí \\
\hline & & $\begin{array}{c}\text { Cytogenetical action } \\
\text { of Paracetamol on } \\
\text { meiotic cells of male } \\
\text { mice. (22) }\end{array}$ & $X$ & 1980 & Resumen & $\begin{array}{c}\text { Animales } \\
\text { (ratas) }\end{array}$ & Sí \\
\hline
\end{tabular}

* Especificamente dirigido a la capacidad reproductora 
todo el homogenizado. Relacionan estos resultados con una posible estimulación del metabolismo testicular y añade que no se puede producir una lesión bioquímica como la depleción del glutatión.

En el tercer estudio (22) se administró a una cepa de ratones machos dosis de $0,625,1,25$ y $2,5 \mathrm{mg}$ de paracetamol durante 5 semanas. Hubo dos series de experimentos, una de una sola dosis y otra serie acumulada de dosis durante 3 días a intervalos de 24 horas. Se observaron tanto autosomas como cromosomas sexuales univalentes durante la primera semana en ambas series y una preponderancia de los autosomas sobre los cromosomas sexuales hasta la cuarta semana. Las poliploidías y translocaciones fueron de baja incidencia.

\section{Ibuprofeno/derivados}

del ácido propiónico

En la primera búsqueda no se obtuvieron resultados relevantes. En ningún caso se obtuvo resultados específicos de ibuprofeno relacionado con la fertilidad masculina por lo que se recurrió a los resultados de prin- cipios activos que están en el mismo grupo terapéutico. Así, en la segunda búsqueda se encontraron 2 estudios referentes a flurbiprofeno y uno referente al oxaprozin, recogidos en la tabla 6 y comentados a continuación.

El primer estudio (23) se realizó en 34 voluntarios sanos. A 12 de ellos se les trató con placebo, otros 12 con oxaprozin y a los 10 restantes con indometacina. Nos centramos en los resultados de oxaprozin ya que es un antiinflamatorio no esteroideo derivado del ácido propiónico al igual que ibuprofeno, mientras que indometacina deriva del indol metilado. Se analizó el conteo de espermatozoides, motilidad, linealidad, velocidad, desplazamiento lateral de cabeza y frecuencia de batido por análisis de imagen computerizado antes del tratamiento y a intervalos semanales durante todo el estudio. Se observó una disminución significativa de prostaglandina en plasma seminal a las 2 semanas de tratamiento y el efecto se prolongó 2 semanas adicionales. Los niveles de testosterona, LH, FSH, TSH, estradiol y prolactina permanecieron sin cambios. La respuesta de hormonas hipofisarias no se vio afectada ni durante ni después del tratamiento. En general se concluye que no hay una influencia negativa de oxaprozin en la función reproductiva masculina.

En el segundo estudio (24) se habla de flurbiprofeno. Se trata de un estudio en el que participaron 272 pacientes con queja por esterilidad que acudieron a un hospital universitario. Se administró $120 \mathrm{mg}$ de flurbiprofeno a 40 de los 164 casos de esterilidad idiopática durante 3 meses. Se mejoró la concentración y la motilidad del esperma. Los niveles de FSH y LH no se vieron afectados entre antes y después de la administración del principio activo. El nivel de testosterona aumentó sin significancia estadística. Se suspendió el tratamiento a 2 pacientes por síntomas digestivos graves.

En el último estudio (25) se estudió el efecto de sulfasalazina, flurbiprofeno y salicilato de lisina en los perfiles de prostaglandina seminal en 6 individuos normales. Sólo sulfasalazina indujo cambios en el esperma, mientras que los antiinflamatorios produjeron más inhibición de las prostaglandinas.

Tabla 6. Derivados del ácido propiónico y su relación con la fertilidad masculina. Resultados de la segunda búsqueda con PubMed

\begin{tabular}{|c|c|c|c|c|c|c|c|}
\hline $\begin{array}{c}\text { Grupo } \\
\text { terapéutico }\end{array}$ & $\begin{array}{c}\text { Principio } \\
\text { activo }\end{array}$ & Título & Tipo estudio & Año & Accesible & Especie & Específico* \\
\hline \multirow{3}{*}{$\begin{array}{l}\text { Derivados del } \\
\text { ácido propiónico }\end{array}$} & Oxaprozin & $\begin{array}{l}\text { Indomethacin and } \\
\text { oxaprozin lower seminal } \\
\text { prostaglandin levels but } \\
\text { do not influence sperm } \\
\text { motion characteristics } \\
\text { and serum hormones } \\
\text { of young healthy men } \\
\text { in a placebo-controlled } \\
\text { double-blind trial. (23) }\end{array}$ & $\begin{array}{l}\text { Aleatorio doble } \\
\text { ciego }\end{array}$ & 1989 & Resumen & Humanos & Sí \\
\hline & Flurbiprofeno & $\begin{array}{l}\text { (The effects of } \\
\text { prostaglandin synthetase } \\
\text { inhibitor on male } \\
\text { infertility). } \\
\text { (Article in Japanese) } \\
\text { (24) }\end{array}$ & $x$ & 1984 & Resumen & Humanos & Si \\
\hline & Flurbiprofeno & $\begin{array}{l}\text { Comparative study of } \\
\text { antiinflammatory drugs } \\
\text { and sulphasalazine in } \\
\text { relation to prostaglandin } \\
\text { E and } 19 \text { hydroxylated } \\
\text { prostaglandin E levels and } \\
\text { human male fertility. (25) }\end{array}$ & Comparativo & 1984 & Resumen & Humanos & Si \\
\hline
\end{tabular}

\footnotetext{
* Especificamente dirigido a la capacidad reproductora.
} 
Atorvastatina/inhibidores de hidroximetilglutaril-coenzima a (HMG-CoA) reductasa

Como resultado de la primera búsqueda encontramos la tabla 7 desarrollada a continuación.

El primer resultado es un artículo publicado en el Journal Andrology en 2005 (26). En él se comentan varios estudios realizados con atorvastatina y su relación con la calidad espermática. En primer lugar se presenta un problema, un médico expone su preocupación sobre el uso de la atorvastatina debido a varios casos en los que se ha encontrado esperma con baja movilidad posteriormente a su uso. En respuesta se argumenta como consecuencia a este hecho la inhibición de la CoQ10 que produce la atorvastatina y se menciona un estudio para justificarlo. Este estudio fue un estudio piloto abierto no controlado sobre varones con astenozoospermia idiopática a los que se les dio un suplemento de CoQ10, el cual mejoró los parámetros de movilidad de espermatozoides. En esta carta se nombran dos estudios más, uno realizado en ratas donde se vio que dosis superiores a las usadas en humanos produjeron aplasia y aspermia en el epidídimo, alteración en el volumen de los testículos y de los parámetros de esperma. El otro estudio fue realizado en perros donde no se encontraron efectos adversos en los parámetros del semen o histopatología del órgano reproductivo. Se concluye mostrando la necesidad de realización de nuevos estudios relacionados con el tema, ya que se encuentran discrepancias en los resultados de los estudios realizados en ratas y perros.

El segundo estudio (27) es la exposición de un caso clínico. Se trata de un hombre de 38 años con un hijo sano y con hiperlipidemia. Se le pautó una dieta, la cual no surtió efecto por lo que se le administró lovastatina consiguiendo reducir el colesterol de 261 a $168 \mathrm{mg} / \mathrm{dL}$. Posteriormente el paciente intenta un embarazo y no lo consigue. Se ve que la concentración de espermatozoides estaba en 3,2 millones/ml. Tras la interrupción del tratamiento con lovastatina la concentración aumentó a 70 millones/ml.

El tercer estudio (28) se trató de una evaluación de la función gonadal y adrenal en sujetos con hipercolesterolemia familiar heterocigota antes y después de 12 semanas de tratamiento con pravastatina. No hay cambios en las respuestas de cortisol en plasma. No se observaron cambios en la testosterona, hormona sexual globulina vinculante, androstenediona, dehidroepiandrosterona sulfato, el estradiol o 17 alfa-hidroxiprogesterona. Niveles de gonadotropina se vieron afectados en 7 sujetos de los 12 tratados con pravastatina. La conclusión fue que ningún efecto adverso sobre la función gonadal o adrenal se pudo demostrar.

Tras la segunda búsqueda se obtuvo un resultado relevante para esta revisión (tabla 8).

Se trató de un estudio (29) realizado en 8 sujetos masculinos con hipercolesterolemia. Todos ellos recibieron una dieta hipocolesterolémica, placebo durante 4 semanas y seguido

Tabla 7. Resultados obtenidos de la primera búsqueda en PubMed que relacionan los Inhibidores de la HMG-coA reductasa y la fertilidad masculina

\begin{tabular}{|c|c|c|c|c|c|c|c|}
\hline Grupo terapéutico & Principio activo & Título & $\begin{array}{c}\text { Tipo } \\
\text { estudio }\end{array}$ & Año & Accesible & Especie & Especifico* \\
\hline \multirow{3}{*}{$\begin{array}{l}\text { Inhibidores } \\
\text { de HMG CoA } \\
\text { reductasa }\end{array}$} & Atorvastatina & $\begin{array}{c}\text { Atorvastatin and male } \\
\text { infertility: is there a link? } \\
(26)\end{array}$ & Carta & 2005 & $\begin{array}{l}\text { No, solicitud a } \\
\text { biblioteca }\end{array}$ & $X$ & Sí \\
\hline & Lovastatina & $\begin{array}{l}\text { Lovastatin and hypospermia. } \\
\qquad(27)\end{array}$ & $\begin{array}{l}\text { Caso } \\
\text { clínico }\end{array}$ & 1990 & $\begin{array}{l}\text { No, solicitud a } \\
\text { biblioteca }\end{array}$ & Humanos & Si \\
\hline & Pravastatina & $\begin{array}{c}\text { Effects of pravastatin and } \\
\text { cholestyramine on gonadal and } \\
\text { adrenal steroid production in } \\
\text { familial hypercholesterolaemia. } \\
\text { (28) }\end{array}$ & $X$ & 1991 & $\begin{array}{c}\text { Texto } \\
\text { completo }\end{array}$ & Humanos & Si \\
\hline
\end{tabular}

* Específicamente dirigido a la capacidad reproductora.

Tabla 8. Resultado de la segunda búsqueda en PubMed. Inhibidores de la HMG-coA reductasa y fertilidad masculina

\begin{tabular}{|c|c|c|c|c|c|c|c|}
\hline $\begin{array}{c}\text { Grupo } \\
\text { terapéutico }\end{array}$ & Principio activo & Título & $\begin{array}{c}\text { Tipo } \\
\text { estudio }\end{array}$ & Año & Accesible & Especie & Especifico* \\
\hline $\begin{array}{l}\text { Inhibidores } \\
\text { de HMG CoA } \\
\text { reductasa }\end{array}$ & Pravastatina & $\begin{array}{c}\text { Effects of long-term } \\
\text { pravastatin treatment } \\
\text { on spermatogenesis and } \\
\text { on adrenal and testicular } \\
\text { steroidogenesis in male } \\
\text { hypercholesterolemic } \\
\text { patients. (29) }\end{array}$ & $X$ & 1998 & Resumen & Humanos & Si \\
\hline
\end{tabular}

* Especificamente dirigido a la capacidad reproductora. 
de pravastatina $(20 \mathrm{mg} /$ día) durante 6 meses. Durante la semana 4 y 5 , y finales de semana 23 y 24 se realizó un análisis de semen además de prueba de hormona liberadora de corticotrofina (CRH), ACTH y hCG. Pravastatina redujo el colesterol total y el colesterol fijado a lipoproteínas de baja densidad (LDL). El cortisol plasmático basal, la aldosterona, androstenediona, testosterona y estradiol no cambiaron en el tratamiento activo. Los análisis de semen fueron normales en cuanto a conteo, morfología y movilidad. Las pruebas de CRH, ACTH y hCG no se vieron afectadas. Se puede decir que el tratamiento a largo plazo con pravastatina, además de mejorar el perfil lipídico, no influye en la fertilidad masculina.

Tamsulosina/antagonistas de receptores alfa adrenérgicos

Los dos primeros estudios se obtuvieron en la primera búsqueda realizada y el tercero fue resultado de la última búsqueda.

En el primer artículo (30) se habla de un estudio realizado en ratones usando antagonistas de receptores alfa1A y antagonistas de los receptores alfa1 (A;B;D). Se llega a la conclusión de que la eyaculación reducida y la infertilidad masculina es consecuencia de una alteración de la función de los vasos deferentes, y no por alteración en la formación del esperma, número o función.
El segundo estudio (31) incluyó a 30 parejas con subfertilidad masculina idiopática de entre 26 y 38 años. A 15 de ellos se les administró $2 \mathrm{mg}$ de terazosina y los otros 15 recibieron placebo durante 6 meses. El volumen seminal varió en ambos grupos, la concentración de espermatozoides aumentó en el grupo con terazosina, no se observó ninguna mejora de la media del porcentaje de espermatozoides anormales en los pacientes tratados, ni una diferencia estadísticamente significativa de la motilidad de los espermatozoides en el grupo tratado.

El tercer estudio (32) se realizó en 48 pacientes sanos que recibieron 5 días $0,8 \mathrm{mg}$ de tamsulosina, $10 \mathrm{mg}$ de alfuzosina y placebo con 10 y 14 dias de periodo de lavado entre tratamiento. Se evaluaron concentración de espermatozoides de semen, el conteo de espermatozoides del semen, la viscosidad del semen, fructosa semen, motilidad de los espermatozoides y la morfología de los espermatozoides en el día 5 de tratamiento. El recuentro de espermatozoides se redujo con tamsulosina, el porcentaje de hombres con viscosidad normal fue menor con tamsulosina, la movilidad se redujo con tamsulosina y el porcentaje de espermatozoides anormales aumentó con tamsulosina. Así, se concluye que tamsulosina tiene un efecto negativo sobre el esperma en hombres sanos.

Resultados anteriores recogidos en tabla 9.
Escitalopram-venlafaxina/ antidepresivos

Estos dos antidepresivos están dentro del mismo grupo terapéutico pero a su vez se clasifican en subgrupos distintos por lo que realizamos una tercera búsqueda de cada uno con su subgrupo. Agrupamos los resultados en dos tablas, la primera (tabla 10) para las dos primeras búsquedas y la segunda (tabla 11) para las búsquedas que incluyen los subgrupos.

En el primer estudio (33) se incluyeron un total de 25 pacientes con queja por eyaculación precoz (un total de 25 pacientes). Tomaron $10 \mathrm{mg}$ de escitalopram al día durante 12 semanas y las visitas de control fueron el primer mes y el tercero. Se midió el tiempo de latencia eyaculatoria (TLE), se realizó el cuestionario herramienta diagnóstica de la eyaculación prematura (PEDT) y se examinaron muestras de semen. En el tercer mes se observó un aumento en las medias de TLE, una disminución en las puntuaciones del PEDT y se observó una disminución de motilidad, morfología y concentración de espermatozoides.

El segundo estudio (34) contó con 35 varones sanos de entre $18 \mathrm{y}$ 65 años. Se les administró paroxetina durante 5 semanas y se analizaron los niveles de hormonas en suero, análisis de semen y evaluación de la fragmentación del ácido desoxirribonucleico (ADN). También se realizó el cuestionario de la función sexual

Tabla 9. Agrupación de los resultados de la primera y segunda búsqueda en PubMed, que relacionan antagonistas alfa-adrenérgicos y fertilidad masculina

\begin{tabular}{|c|c|c|c|c|c|c|c|}
\hline Grupo terapéutico & Principio activo & Título & $\begin{array}{c}\text { Tipo } \\
\text { estudio }\end{array}$ & Año & Accesible & Especie & Específico* \\
\hline \multirow{3}{*}{$\begin{array}{l}\text { Antagonistas } \\
\text { receptores alfa } \\
\text { adrenérgicos }\end{array}$} & Tamsulosina & $\begin{array}{l}\text { Alpha1-adrenoceptors and } \\
\text { ejaculatory function. (30) }\end{array}$ & $X$ & 2007 & $\begin{array}{c}\text { Texto } \\
\text { completo }\end{array}$ & $\begin{array}{l}\text { Animales } \\
\text { (ratones) }\end{array}$ & Si \\
\hline & Terazosina & $\begin{array}{c}\text { Treatment of idiopathic } \\
\text { oligozoospermia with an } \\
\text { alpha-blocker: a placebo- } \\
\text { controlled double-blind trial. } \\
\text { (31) }\end{array}$ & $\begin{array}{c}\text { Doble } \\
\text { ciego } \\
\text { controlado } \\
\text { con } \\
\text { placebo }\end{array}$ & 1997 & Resumen & Humanos & Sí \\
\hline & Tamsulosina & $\begin{array}{l}\text { Effects of alfuzosin and } \\
\text { tamsulosin on sperm } \\
\text { parameters in healthy men: } \\
\text { results of a short-term, } \\
\text { randomized, double- } \\
\text { blind, placebo-controlled, } \\
\text { crossover study. (32) }\end{array}$ & $\begin{array}{l}\text { Aleatorio, } \\
\text { cruzado } \\
\text { múltiple, } \\
\text { doble } \\
\text { ciego }\end{array}$ & 2009 & $\begin{array}{c}\text { Texto } \\
\text { completo }\end{array}$ & Humanos & Si \\
\hline
\end{tabular}

* Específicamente dirigido a la capacidad reproductora. 
Tabla 10. Resultados a partir de las búsquedas en PubMed que relacionan antidepresivos y fertilidad masculina

\begin{tabular}{|c|c|c|c|c|c|c|c|}
\hline Grupo terapéutico & Principio activo & Título & $\begin{array}{l}\text { Tipo } \\
\text { estudio }\end{array}$ & Año & Accesible & Especie & Especifico* \\
\hline \multirow{4}{*}{ Antidepresivos } & Escitalopram & $\begin{array}{l}\text { Escitalopram treatment } \\
\text { for premature ejaculation } \\
\text { has a negative effect on } \\
\text { semen parameters. (33) }\end{array}$ & $X$ & 2011 & Resumen & Humanos & Si \\
\hline & Paroxetina & $\begin{array}{l}\text { Adverse effect of } \\
\text { paroxetine on sperm. (34) }\end{array}$ & Prospectivo & 2009 & Resumen & Humanos & Si \\
\hline & Sertralina & $\begin{array}{l}\text { Comparison of the } \\
\text { effect of sertraline with } \\
\text { behavioral therapy on } \\
\text { semen parameters in men } \\
\text { with primary premature } \\
\text { ejaculation. (35) }\end{array}$ & $\begin{array}{l}\text { Simple } \\
\text { ciego }\end{array}$ & 2014 & Resumen & Humanos & Si \\
\hline & Citalopram & $\begin{array}{l}\text { Citalopram at the } \\
\text { recommended human } \\
\text { doses after long-term } \\
\text { treatment is genotoxic for } \\
\text { male germ cell. (36) }\end{array}$ & $x$ & 2013 & Resumen & $\begin{array}{l}\text { Animales } \\
\text { (ratones) }\end{array}$ & Si \\
\hline
\end{tabular}

* Específicamente dirigido a la capacidad reproductora.

Tabla 11. Búsqueda en PubMed de los subgrupos terapéuticos de los antidepresivos y su influencia en la fertilidad masculina

\begin{tabular}{|c|c|c|c|c|c|c|c|}
\hline Grupo terapéutico & $\begin{array}{l}\text { Subgrupo } \\
\text { terapéutico }\end{array}$ & Título & $\begin{array}{l}\text { Tipo } \\
\text { estudio }\end{array}$ & Año & Accesible & Especie & Especifico* \\
\hline \multirow[t]{3}{*}{ Antidepresivos } & $\begin{array}{l}\text { Inhibidores } \\
\text { recaptación } \\
\text { de serotonina } \\
\text { (escitalopram) }\end{array}$ & $\begin{array}{l}\text { Sperm DNA damage and } \\
\text { semen quality impairment } \\
\text { after treatment with } \\
\text { selective serotonin } \\
\text { reuptake inhibitors } \\
\text { detected using semen } \\
\text { analysis and sperm } \\
\text { chromatin structure assay. } \\
\text { (37) }\end{array}$ & $x$ & 2008 & Resumen & Humanos & Si \\
\hline & $\begin{array}{c}\text { Otros } \\
\text { antidepresivos } \\
\text { (venlafaxina) }\end{array}$ & $x$ & $x$ & $x$ & $x$ & $x$ & $x$ \\
\hline & $\begin{array}{c}\text { Otros } \\
\text { antidepresivos } \\
\text { (duloxetina) }\end{array}$ & $x$ & $x$ & $X$ & $x$ & $x$ & $x$ \\
\hline
\end{tabular}

* Especificamente dirigido a la capacidad reproductora.

antes, durante, y 1 mes después de la administración del fármaco. Aumentó la fragmentación, hubo cambios significativos en la función eréctil y dificultad eyaculatoria. Los parámetros seminales no se vieron alterados de forma significativa. Los valores alterados se restauraron después de la suspensión del tratamiento.

El tercer estudio (35) recogido se realizó sobre 60 pacientes con eya- culación precoz primaria. Se hicieron dos grupos, a uno se le dio $25 \mathrm{mg}$ de sertralina al día durante una semana seguido de $50 \mathrm{mg}$ al día durante $3 \mathrm{me}$ ses, el otro grupo participó durante 3 meses en una terapia conductual. Se realizó análisis de semen antes y 3 meses después de la intervención. Se encontró una reducción significativa de la concentración de esperma, un aumento de la fragmentación y una dis- minución del porcentaje de morfología normal. No se observaron cambios en el grupo con terapia conductual.

En el cuarto estudio (36) se trató a ratones macho con citalopram durante 4-8 semanas con dosis de 6, 12 y $24 \mathrm{mg} / \mathrm{Kg} /$ día. Las dosis de 12 y $24 \mathrm{mg}$ produjeron un aumento de la ruptura de hebras de $\mathrm{ADN}$, espermatocitos primarios aberrantes y daño oxidativo de ADN. 
Tabla 12. Relación entre levetiracetam y fertilidad masculina. Resultados de la primera búsqueda en PubMed

\begin{tabular}{|c|c|c|c|c|c|c|c|}
\hline Grupo terapéutico & Principio activo & Título & $\begin{array}{l}\text { Tipo } \\
\text { estudio }\end{array}$ & Año & Accesible & Especie & Especifico* \\
\hline \multirow{2}{*}{$\begin{array}{c}\text { Otros } \\
\text { antiepilépticos }\end{array}$} & Levetiracetam & $\begin{array}{l}\text { Effects of antiepileptic drugs on } \\
\text { reproductive endocrine function, } \\
\text { sexual function and sperm } \\
\text { parameters in Chinese Han men } \\
\text { with epilepsy. (38) }\end{array}$ & $X$ & 2013 & Resumen & Humanos & Si \\
\hline & Levetiracetam & $\begin{array}{l}\text { Effects of levetiracetam and } \\
\text { valproic acid monotherapy on sex- } \\
\text { steroid hormones in prepubertal } \\
\text { children--results from a pilot } \\
\text { study. (39) }\end{array}$ & $\begin{array}{l}\text { Estudio } \\
\text { piloto }\end{array}$ & 2010 & Resumen & Humanos & Si \\
\hline
\end{tabular}

* Especificamente dirigido a la capacidad reproductora.

Se obtuvo un resultado relevante de la búsqueda relacionada con los inhibidores de la recaptación de serotonina, sin embargo no hubo ningún resultado en la búsqueda que relacionaba venlafaxina con la fertilidad masculina, ni la búsqueda que relacionaba duloxetina con la fertilidad masculina. Los resultados de la búsqueda fueron "no items found".

En cuanto al estudio mencionado (37), éste tenía una muestra de 74 hombres fértiles con depresión y tratados con inhibidores de la recaptación de serotonina, y 44 voluntarios sanos fértiles que sirvieron como control. Se les realizaron dos análisis de semen y exámenes físicos. La media del número total de espermatozoides fue menor en el grupo tratado, su motilidad más baja y hubo un aumento significativo de cantidad de ADN con cadena desnaturalizada.

\section{Clopidogrel/inhibidores} agregación plaquetaria

No encontramos estudios de interés dentro de los resultados de las búsquedas realizadas.

Valsartán-candesartán-irbesartán/ antagonistas angiotensina II

No encontramos estudios de interés dentro de los resultados de las búsquedas realizadas. Los resultados obtenidos hablaban del efecto de la angiotensina II en la fertilidad masculina, por ejemplo en la reacción acrosómica del espermatozoide, pero en ningún caso aparecieron estudios realizados con ninguno de los medicamentos aparecidos en nuestra lista o que pertenezcan al grupo terapéutico.

\section{Bromuro de tiotropio/ anticolinérgico}

No encontramos estudios de interés dentro de los resultados de las búsquedas realizadas.

\section{Ácido risedrónico-ácido ibandrónico/bifosfonatos}

No se encontraron resultados de interés en las búsquedas realizadas en la base de datos.

\section{Citicolina/psicoestimulantes y nootrópicos}

En la primera búsqueda los resultados obtenidos no eran de interés y en la segunda búsqueda el resultado fue "no items found".

\section{Pregabalina-levetiracetam/otros antiepilépticos}

En la primera búsqueda solo obtuvimos resultados referentes a levetiracetam, ninguno en relación a pregabalina (tabla 12).

En el primer estudio (38) se exploró el efecto de levetiracetam en la función endocrina, función sexual y afección de espermatozoides en hombres chinos. Levetiracetam solo produjo alteración en el test de Escala de Función Eréctil, donde se obtuvieron puntuaciones más bajas en algunas preguntas en comparación al grupo control.
El segundo estudio (39) se realizó en 30 niños prepúberes y el objetivo era ver la influencia del levetiracetam sobre la hormona esteroide sexual. La concentración de androstendiona fue ligeramente superior en comparación con el grupo control. Se concluyó que levetiracetam no parece inducir cambios en las funciones endocrinas reproductivas.

\section{Montelukast/antagonistas} del receptor de leucotrienos

En la primera búsqueda no hubo resultados, PubMed mostró "no items found”. En la segunda búsqueda se obtuvieron 3 resultados, de los cuales 1 fue de interés (40). Se muestra en la tabla 13. Se evaluó el efecto protector del montelukast sobre la toxicidad reproductiva producida por el cisplatino. Se realizó con 28 ratas que fueron dividas en 4 grupos. El primero fue grupo control, al segundo se le administró cisplatino vía oral durante 10 días, al tercero se le administró cisplatino intraperitoneal una sola inyección y el cuarto grupo recibió cisplatino junto con montelukast a la misma dosis. En el grupo con montelukast se observó un aumento de glutatión peroxidasa (GSH), superóxido dismutasa (SOD) y catalasa (CAT). Hubo una disminución en la formación de sustancias reactivas al ácido barbitúrico (TBARS). Además la motilidad del esperma y los niveles de testosterona afectados por el tratamiento con cisplatino fueron eliminados con el tratamiento de montelukast. En conclusión la coadministración de montelukast con cisplatino puede ser útil para atenuar los efectos negativos del cisplatino en el sistema reproductor masculino. 
Tabla 13. Resultado obtenido de la segunda búsqueda a través de PubMed. Montelukast y la disminución de la toxicidad reproductiva por cisplatino

\begin{tabular}{|c|c|c|c|c|c|c|c|}
\hline Grupo terapéutico & Principio activo & Título & $\begin{array}{c}\text { Tipo } \\
\text { estudio }\end{array}$ & Año & Accesible & Especie & Especifico* \\
\hline $\begin{array}{c}\text { Antagonistas } \\
\text { del receptor de } \\
\text { leucotrienos }\end{array}$ & Montelukast & $\begin{array}{c}\text { Montelukast attenuates side } \\
\text { effects of cisplatin including } \\
\text { testicular, spermatological, and } \\
\text { hormonal damage in male rats. } \\
(40)\end{array}$ & $X$ & 2012 & $\begin{array}{c}\text { Resumen } \\
\text { (ratas) }\end{array}$ & $\begin{array}{c}\text { Animales } \\
\text { Si }\end{array}$ \\
\hline
\end{tabular}

* Especificamente dirigido a la capacidad reproductora.

\section{Fentanilo/anestésicos opioides}

Como resultado de nuestra búsqueda no obtuvimos ninguno referente al fentanilo, pero sí referente a remifentanilo que forma parte del mismo grupo terapéutico (tabla 14).

El primer estudio (41) tenía como objetivo observar los efectos de remifentanilo sobre la motilidad del esperma humano in vitro. Los espermatozoides fueron tratados con remifentanilo in vitro durante 30 minutos. La motilidad del esperma se analizó a los 5, 10, 15 y 30 minutos. Se observó una disminución del grado de movilidad entre el minuto 5 y 10 . No hubo diferencia significativa con el grupo control entre el minuto 15 y 30.

En el segundo estudio (41) se recogieron muestras de semen (no se especifica la especie aunque damos por hecho que se trata de muestras de humanos) y se trataron in vitro con remifentanilo y remifentanilo+naloxona durante 35 minutos. En comparación con el grupo control remifentanilo disminuyó significativamente la motilidad del esperma en el minuto 5 y 10 de forma dosis-dependiente y con ninguna diferencia significativa a los 15 y 30 minutos. La conclusión fue que el inicio y final del efecto de remifentanilo en la motilidad del esperma son rápidos y su efecto inhibidor se puede antagonizar por la naloxona.

\section{Risperidona-quetiapina- olanzapina/antipsicóticos}

Realizamos más de dos búsquedas, ya que dentro del grupo de los antipsicóticos risperidona pertenece a un subgrupo y quetiapina junto con olanzapina pertenecen a otro. Así se hizo una primera búsqueda con los tres principios activos + "male fertility" y dos búsquedas más con los principios activos del mismo subgrupo + "sperm"."

En la primera búsqueda, PubMed solo mostró un resultado (43) que a su vez resultó ser de nuestro interés (tabla 15). Se incluyeron a 89 pacientes esquizofrénicos tratados con olanzapina o risperidona por vía oral. Se evaluaron niveles de prolactina, inhibina b, estradiol, testosterona, LH y FSH. También se evaluó la psicopatología, la función sexual y la adherencia al tratamiento. Todo esto en la semana 3 y 8 después del inicio del tratamiento. En la evaluación inicial se encontraron niveles de prolactina e inhibina superiores, los niveles de testosterona fueron menores en los pacientes tratados con risperidona. La prolactina en suero fue significativamente mayor en los pacientes

Tabla 14. Relación entre anestésicos opioides y fertilidad masculina

\begin{tabular}{|c|c|c|c|c|c|c|c|}
\hline Grupo terapéutico & Principio activo & Título & $\begin{array}{c}\text { Tipo } \\
\text { estudio }\end{array}$ & Año & Accesible & Especie & Específico* \\
\hline \multirow[b]{2}{*}{$\begin{array}{l}\text { Anestésicos } \\
\text { opioides }\end{array}$} & Remifentanilo & $\begin{array}{l}\text { Remifentanil impairs sperm } \\
\text { motility reversibly in vitro. (41) }\end{array}$ & $X$ & 2012 & Resumen & Humanos & Si \\
\hline & Remifentanilo & $\begin{array}{l}\text { (Effects of remifentanil combined } \\
\text { with naloxone on human sperm } \\
\text { motility). } \\
\text { (Article in Chinese) (42) }\end{array}$ & $X$ & 2011 & Resumen & $\begin{array}{l}\text { X (esperma } \\
\text { normal) }\end{array}$ & Si \\
\hline
\end{tabular}

* Especificamente dirigido a la capacidad reproductora.

Tabla 15. Primera búsqueda en PubMed que relaciona antipsicóticos y fertilidad masculina

\begin{tabular}{|c|c|c|c|c|c|c|c|}
\hline Grupo terapéutico & Principio activo & Título & $\begin{array}{c}\text { Tipo } \\
\text { estudio }\end{array}$ & Año & Accesible & Especie & Especifico* \\
\hline Antipsicóticos & $\begin{array}{c}\text { Risperidona y } \\
\text { olanzapina }\end{array}$ & $\begin{array}{l}\text { Effect } \\
\text { of risperidone and olanzapine on } \\
\text { reproductive hormones, } \\
\text { psychopathology and sexual } \\
\text { functioning in male patients with } \\
\text { schizophrenia. (43) }\end{array}$ & $X$ & 2009 & Resumen & Humanos & Si \\
\hline
\end{tabular}

* Específicamente dirigido a la capacidad reproductora. 
que tomaron risperidona, mientras que sus niveles de FSH fueron menores que en los pacientes tratados con olanzapina. La media de LH, FSH, testosterona y estradiol estaba dentro del rango normal de referencia en la evaluación inicial y final. En conclusión, los pacientes tratados con risperidona mostraron mayor nivel de disfunción sexual.

En la segunda búsqueda realizada con la risperidona se obtuvieron 2.384 resultados. Debido al gran volumen se añadieron filtros a la búsqueda, éstos fueron: text availability: "free full text", publication dates: "5 years", species: "humans". Se redujo la cifra a 114 . De todos ellos encontramos 2 de relevancia para esta revisión (tabla 16).

El primer estudio (44) incluyó a 481 esquizofrénicos tratados con risperidona (N-172), olanzapina (N-211) y ziprasidona (N-98). En el estudio se miró la relación entre la ocupación de receptor D2 y la concentración de prolactina. La ocupación del receptor D2 de dopamina fue significativamente mayor en los sujetos que experimentaron hiperprolactinemia. De este estudio lo que nos interesa saber es que la medicación utilizada tiene como efecto secundario la hiperprolactinemia que es motivo de esterilidad masculina. Fueron víctimas de este efecto secundario 170 pacientes de los 481 .

El segundo estudio (45) contó con niños desde 6 años hasta 15 con trastorno bipolar I desde 2003 hasta 2008. El protocolo de tratamiento fue de 8 semanas. Finalmente se trató de una muestra de 279 sujetos. Hubo un mayor aumento de peso, de masa corporal y de prolactina con la risperidona que con litio. Resultó ser más eficaz para el tratamiento pero con efectos metabólicos potencialmente graves.

En la tercera búsqueda PubMed proporcionó un resultado (46) al eliminar los filtros. Éste resultó ser de nuestro interés (tabla 17). Olanzapina actúa sobre receptores dopaminérgicos los cuales se encuentran también en células germinales, por este motivo en este estudio se investiga los efectos del tratamiento con diferentes dosis de olanzapina sobre la espermatogénesis, la testosterona plasmática y peso de los órganos dependientes de andrógenos en las ratas. Los resultados mostraron niveles reducidos de testosterona en plasma, reducción de testículos, epidídimo y peso de la próstata. Además se determinó degeneración testicular. Se vio descamación de células germinales, vacuolización de células de sertoli y presencia de cé- lulas germinales necróticas y apoptóticas. En conclusión, olanzapina produjo una perturbación de la espermatogénesis.

\section{Ezetimiba/otros agentes} reductores del colesterol y los triglicéridos

Se suponía que este principio activo se agruparía con los resultados de atorvastatina. Decidimos realizar su búsqueda aparte porque se obtuvieron muchos resultados de los inhibidores de la HMG Coa reductasa. Realizamos dos búsquedas independientes para ezetimiba. En los resultados de la primera búsqueda no encontramos ninguno de interés, aparecieron algunos ya comentados anteriormente en el apartado de las estatinas. En la segunda búsqueda sucedió lo mismo. En ningún caso apareció un estudio que incluyera ezetimiba.

\section{Insulina glargina/ insulinas y} análogos de acción prolongada

Tanto en la primera como en la segunda búsqueda se puso, además del principio activo, el término "insulin long-acting”. PubMed no mostró resultados en ninguna de las dos búsquedas. El resultado obtenido fue " $n o$ items found".

Tabla 16. Resultados de la búsqueda en PubMed por subgrupo terapéutico. Risperidona y su influencia en la fertilidad masculina

\begin{tabular}{|c|c|c|c|c|c|c|}
\hline Principio activo & Título & $\begin{array}{c}\text { Tipo } \\
\text { estudio }\end{array}$ & Año & Accesible & Especie & Específico* \\
\hline \multirow[b]{2}{*}{ Risperidona } & $\begin{array}{l}\text { Hyperprolactinemia and estimated dopamine D2 } \\
\text { receptor occupancy in patients with schizophrenia: } \\
\text { analysis of the CATIE data. (44) }\end{array}$ & X & 2013 & $\begin{array}{c}\text { Texto } \\
\text { completo }\end{array}$ & Humanos & No \\
\hline & $\begin{array}{c}\text { A randomized controlled trial of risperidone, lithium, } \\
\text { or divalproex sodium for initial treatment of bipolar } \\
\text { I disorder, manic or mixed phase, in children and } \\
\text { adolescents. (45) }\end{array}$ & $\begin{array}{l}\text { Ensayo } \\
\text { clínico } \\
\text { aleatorio } \\
\text { controlado }\end{array}$ & 2012 & $\begin{array}{c}\text { Texto } \\
\text { completo }\end{array}$ & Humanos & No \\
\hline
\end{tabular}

* Especificamente dirigido a la capacidad reproductora.

Tabla 17. Resultados de la búsqueda de antipsicóticos y su relación con la fertilidad masculina por subgrupo terapéutico (olanzapina y quetiapina)

\begin{tabular}{|c|c|c|c|c|c|c|}
\hline Principio activo & Título & $\begin{array}{l}\text { Tipo } \\
\text { estudio }\end{array}$ & Año & Accesible & Especie & Especifico* \\
\hline Olanzapina & $\begin{array}{l}\text { Endocrine and testicular } \\
\text { changes induced } \\
\text { by olanzapine in adult Wistar } \\
\text { rats. (46) }\end{array}$ & $X$ & 2013 & Resumen & $\begin{array}{c}\text { Animales } \\
\text { (ratas) }\end{array}$ & Sí \\
\hline Quetiapina & $x$ & $x$ & $x$ & $x$ & $x$ & $x$ \\
\hline
\end{tabular}

* Específicamente dirigido a la capacidad reproductora. 
Enoxaparina/grupo

de la heparina

De la primera búsqueda se obtuvieron 2 artículos que no resultaron de interés y de la segunda un artículo que tampoco estaba relacionado con el tema.

La tabla resumen (tabla 18) presenta una comparativa de los resultados obtenidos respecto a la fertilidad masculina a través de las fuentes utilizadas. Se diferencia entre resultados positivos (representados en la tabla con un “+”). Son los medicamentos que no afectan a la fertilidad masculina según la revisión realizada. Resultados negativos (representados en la tabla con un "-“). Son los principios activos cuya toxicidad reproductiva masculina está registrada en alguna de las fuentes consultadas. Por último, el símbolo de la "X", el cual refleja la falta de resultados, o bien en la ficha técnica o bien en la base de datos de PubMed (según nuestro patrón de búsqueda).

\section{Discusión}

La infertilidad es un problema de salud cada vez más presente en la sociedad y los medicamentos son sustancias que conviven con la sociedad. La población está sobreexpuesta a ellos y debe ser un factor a tener en cuenta en las múltiples causas de esterilidad. Esto es lo que motiva la realización de esta revisión bibliográfica, la cual se centra en el sexo masculino ya que parece quedar muchas veces en un segundo plano. Se ha querido analizar detenidamente hasta qué punto la información proporcionada por las fichas técnicas es transparente, clara y completa con respecto a la repercusión de los medicamentos en la fertilidad masculina. Con este trabajo se pretende completar y complementar información y proporcionar datos específicos mediante la revisión de los distintos estudios hallados. En definitiva, se ha querido crear una guía que sea de utilidad para el facultativo cuando explore el historial clínico del paciente en una primera consulta. Que sirva a la hora de considerar o descartar causas de una posible infertilidad.

En este trabajo podemos ver cómo el medicamento más consumido en España, el omeprazol, con 51.874 (miles de unidades) envases dispensados en 2010, no presenta en

Tabla 18. Tabla resumen. Comparativa de los resultados obtenidos a través de las fuentes de estudio

\begin{tabular}{|c|c|c|}
\hline Principio activo & $\begin{array}{c}\text { Información en ficha } \\
\text { técnica }\end{array}$ & $\begin{array}{l}\text { Resultados de las búsquedas } \\
\text { en PubMed }\end{array}$ \\
\hline Omeprazol & $x$ & + \\
\hline Pantoprazol & $x$ & + \\
\hline Esomeprazol & $x$ & $x$ \\
\hline Lansoprazol & $x$ & + \\
\hline Paracetamol & - & - \\
\hline Ibuprofeno & $x$ & $x$ \\
\hline Atorvastatina & + & - \\
\hline Tamsulosina & $x$ & - \\
\hline Escitalopram & $\begin{array}{c}-(\text { animales)/+ } \\
\text { (humanos) }\end{array}$ & $-1-$ \\
\hline Venlafaxina & - & $x$ \\
\hline Duloxetina & + & $x$ \\
\hline Clopidogrel & + & $x$ \\
\hline Valsartán & $x$ & $x$ \\
\hline Candesartán & $x$ & $x$ \\
\hline Irbesartán & + & $x$ \\
\hline B. Tiotropio & + & $x$ \\
\hline A. Risedrónico & - & $x$ \\
\hline A. Ibandrónico & $x$ & $x$ \\
\hline Citicolina & $x$ & $x$ \\
\hline Pregabalina & - & $x$ \\
\hline Levetiracetam & + & + \\
\hline Montelukast & + & + \\
\hline Fentanilo & $x$ & $x$ \\
\hline Risperidona & $x$ & - \\
\hline Quetiapina & $x$ & $x$ \\
\hline Olanzapina & $x$ & - \\
\hline Ezetimiba & $x$ & $x$ \\
\hline Insulina glargina & + & $x$ \\
\hline Enoxaparina & + & $x$ \\
\hline
\end{tabular}

$X=$ No resultados obtenidos.

$+=$ Resultados positivos, en la fuente consultada se indica que no afectan a la fertilidad masculina según los datos disponibles.

- = Resultados negativos, son los principios activos cuya toxicidad reproductiva masculina está registrada la fuente consultada.

su ficha técnica ningún dato referente a la fertilidad masculina. Esto ha sucedido en 15 de los 29 principios activos que hemos estudiado. También podemos ver como el paracetamol, que es el segundo en la lista y un medicamento dispensado en las farmacias sin necesidad de prescripción médica, cuenta con estudios que indican efectos negativos que podrían ser causa de esterilidad. Se indica en su ficha técnica y lo corroboramos con nuestros resultados de búsqueda. Otro gran consumido como es el ibuprofeno, no cuenta con información en su ficha técnica pero tampoco se consiguió ningún resultado según el patrón de búsqueda establecido. Casos como el de ibuprofeno, en los que no disponemos de material de información que provenga de ninguna de las dos fuentes de las que utilizamos, 
se sucedieron en 9 de los 29 fármacos totales. Sin embargo en 3 de ellos (ibuprofeno, fentanilo y quetiapina) registramos resultados de principios activos recogidos dentro del mismo grupo terapéutico, con el fin de que pudieran ser orientativos.

En 5 de los 29 medicamentos obtuvimos información de las dos fuentes (AEMPS y PubMed) y la información coincidía entre sí en 3 principios activos que fueron: paracetamol, levetiracetam y montelukast. Los 2 restantes, atorvastatina y escitalopram, fueron los únicos donde hubo discrepancias en los resultados. En atorvastatina la ficha técnica lo muestra como un medicamento seguro en cuanto a la fertilidad masculina basándose en estudios con perros, ratas y conejos, sin embargo en nuestros resultados se recoge un artículo en el que se nombran 2 estudios, 1 en ratas y otro en perros, que muestran resultados distintos. Positivos para una especie y negativos para la otra. Además encontramos un caso clínico con lovastatina (mismo grupo terapéutico) en el que ésta parecía influir negativamente en la concentración total de espermatozoides, y otro estudio con pravastatina que decía no influir en la fertilidad masculina. Estos resultados llevan a pensar en la necesidad de nuevos estudios que relacionen estatinas con fertilidad masculina. Estudios que sean válidos y que puedan extrapolarse a la población general. En el caso de escitalopram los resultados de PubMed mostraron resultados claramente negativos en cuanto a la calidad espermática, eyaculación e integridad del ADN, tanto en humanos como en animales, mientras que en la ficha técnica se habla de una alteración del esperma en animales y se puntualiza con que no hay impacto en humanos. Hay que mencionar también que escitalopram y pregabalina son los únicos en los que sus fichas técnicas mencionan reversibilidad de los efectos negativos. El saber si los efectos negativos son reversibles o no, es un dato del que sería muy interesante disponer, ya que influiría en el diagnóstico y resolución del problema de esterilidad y sería de gran utilidad.

En una revisión publicada en 2013 por Human Reproduction (47) encontramos resultados muy interesantes. Se trató de una revisión tradicional en la que los autores tuvieron múltiples conversaciones telefónicas e intercambio de correos electrónicos, se obtuvo información a partir de libros y archivos y se suplementó con búsquedas en PubMed y Google. Se revisaron en profundidad los factores que pueden afectar a la fertilidad masculina. Entre ellos, por supuesto, encontramos un apartado de fármacos con una tabla muy interesante, ya que no sólo aporta información sobre si hay o no efectos en la fertilidad sino que se registran los efectos en el esperma con las entradas: motilidad, capacitación, reacción acrosómica, vitalidad y ADN/cromatina. Sin embargo no especifican los principios activos y tampoco hay un criterio de selección de los grupos seleccionados (se supone que son los más comunes). En la lista encontramos en común con la nuestra los psicótropos, analgésicos opioides y estatinas, $\mathrm{y}$ además incluye a los inhibidores de los canales de calcio y a inhibidores de la fosfodiesterasa. Fuera de la tabla añade también agentes quimioterapéuticos, colchicina, finasterida, sulfasalazina y testosterona y anabolizantes. Podemos ver cómo en el caso de las estatinas, en el que había discrepancias con los resultados obtenidos, dice no haber identificado efectos adversos en el esperma. En la colchicina se hace referencia al mismo estudio del año 98 al que hicimos referencia en la introducción (12). En términos generales los resultados de ambas revisiones coinciden, además su revisión se extiende con drogas de abuso, vitaminas, disruptores endocrinos y productos de uso diarios. Se comenta la necesidad de la evaluación de una posible espermotoxicidad en los productos de uso diario, como pueden ser los cosméticos, ya que en su composición pueden contener sustancias que afecten negativamente a la fertilidad. Además, se comentan las metodologías de distintos test de toxicidad y protocolos.

En cuanto a las limitaciones de la revisión encontramos varias. La consideración de los fármacos más consumidos como criterio de selección de principios activos a estudiar, teniendo en cuenta que los principales consumidores de fármacos son los ancianos, hace centrar la atención en grupos terapéuticos no tan relevantes. El patrón de búsqueda fue una de ellas ya que el hecho de haberse ceñido a la metodología establecida ha impedido profundizar en la búsqueda de los principios activos que no tenían resultados, aunque en algunos casos se alteró de forma mínima. Otra limitación fue que nuestra revisión no incluyó una evaluación de la calidad de los estudios, nos basamos exclusivamente en las conclusiones del autor y esto podría sesgar los resultados. En cuanto a los medicamentos incluidos en la revisión, se seleccionaron los más consumidos en España según el Sistema Nacional de Salud y se reordenaron y clasificaron en función del número de envases dispensados en el año 2010. Según esta clasificación consideramos el primero como el más consumido y el último como el menos, pero habría sido más acertado o sería más interesante haber conseguido una lista de medicamentos ordenados por el número de usuarios en función de la dosis diaria definida (DDD), ya que no todos los envases tienen el mismo número de comprimidos ni la misma concentración. Una dificultad encontrada fue que en la gran mayoría de los casos sólo se disponía de los resúmenes de los estudios y en algunos incluso ni el resumen. Cuando esto último sucedió solicitamos el artículo a la biblioteca del Hospital General de Alicante. También encontramos dificultades a la hora de trabajar con las fichas técnicas, ya que en estas se mencionan estudios pero no se dan referencias de ellos, además en muchas ocasiones hay una desorganización de la información que puede confundir.

Sería muy interesante continuar con este trabajo, ampliar el estándar de búsqueda y completar la información que falta, como ampliar el número de fármacos, el número de fuentes y la estrategia de búsqueda para así elaborar una guía completa con información clara, concisa y contrastada que sirva de referencia rápida y que incluya una síntesis de la ficha técnica y de la información de PubMed de todos los medicamentos del mercado. A partir de aquí se podrían abrir nuevas áreas de investigación centrándose en grupos terapéuticos, en efectos adversos negativos concretos, en dosis y en grupo de población. Una recomendación para un estudio futuro es considerar los grupos terapéuticos más utilizados en el rango de edad en el que la infertilidad es un problema. 
La infertilidad masculina es un hecho y la falta de información referente a los efectos adversos de los medicamentos en este tema también, ya que lo hemos comprobado con esta revisión. Hay datos confusos, falta de estudios, poca transparencia y necesidad de creación de guías completas y actualizadas que recojan información que sea de utilidad para el asesoramiento reproductivo. Podemos ver cómo en las fichas técnicas la fertilidad es un tema infraconsiderado, ya que muchas veces ni es referido y esto conlleva lagunas de conocimiento. Esta revisión puede servir para dar paso a nuevas áreas de investigación que se centren en un determinado grupo terapéutico, un efecto adverso concreto o un fármaco de interés.

\section{Conclusión}

1. Las fichas técnicas de los medicamentos frecuentemente carecen de información sobre la capacidad del medicamento para afectar a la capacidad reproductiva masculina.

2. En ocasiones esta información es incluso contradictoria con la información rescatada de bases de datos públicamente accesibles como PubMed.

3. Ante casos de infertilidad masculina, se debe considerar a los medicamentos como causa potencial.

\section{Referencias bibliográficas}

1. Zegers-Hochschild F, Adamson GD, de Mouzon J, Ishihara 0, Mansour R, Nygren K, et al. Glosario de terminología en Técnicas de Reproducción Asistida (TRA). Versión revisada y preparada por el International Committee for Monitoring Assisted Reproductive Technology (ICMART) y la Organización Mundial de la Salud (OMS) [Internet]. Red Latinoamericana de Reproducción Asistida, 2010. [Acceso 12/1/2015]. Disponible en: http://www.who.int/reproductivehealth/publications/infertility/ art_terminology_es.pdf

2. Rowe PJ, Comhaire FH, Hargreave TB, Mahmoud AMA. WHO manual for the standardized investigation, diagnosis and management of the infertile male. Cambridge: World Health Organization; 2000.

3. Tapia Serrano R. Una visión actual de la infertilidad masculina. Rev Mex Reprod. 2012;4(3):103-109.

4. Jungwirth A, Diemer T, Dohle GR, Giwercman A, Kopa Z, Tournaye H.
Guidelines on male infertility [Internet]. Arnhem (The Netherlands): European Association of Urology (EAU); 2013 Mar. [Acceso 12/1/2015]. Disponible en: http://www.guideline.gov/ content.aspx?id=45325

5. Owalabi AT, Fasubaa OB, Ogunniyi So. Semen quality of male partners of infertile couples in IIe-Ife, Nigeria. Niger J Clin Pract. 2013;16:37-40.

6. Lepecka-Llusek C, Wdowiak A, Pilewska AB, Syty K, Jakiel G. The role of age, environmental and occupational factors on semen density. Annals of Agricultural and Environmental Medicine. 2011;18:437-440.

7. Nguyen RHN, Wilcox AJ, Skjaerven R, Baird DD. Men's body mass index and infertility. Human Reproduction. 2007;22:2488-2493.

8. Retto de Queiroz EK, Waissmann W. Occupational exposure and effects on male reproductive system. Cad. Saúde Pública. 2006;22:485-493.

9. Fronczak CM, Kim ED and Barqawi AB. The insults of illicit drug use on male fertility. Journal of andrology. 2012;33:515-528.

10. Gazvani MR, Bickett W, Luckas MJM, Aird IA, Hipkin LJ, Lewis-Jones DI. Conservative management of azoospermia following steroid abuse. $\mathrm{Hu}-$ man Reproduction. 1997;12:17061708.

11. Sanfélix-Gimeno G, Peiró S, Meneu R. La prescipción farmacéutica en atención primaria. Informe SESPAS 2012. Gac. Sanitaria, 2012;26;41-45.

12. Kristensen DM, Hass U, Lesné L, Lottrup G, Jacobsen PR, Desdoits-Lethimonier $\mathrm{C}$, et al. Intrauterine exposure to mild analgesics is a risk factor for development of male reproductive disorders in human and rat. Hum. Reprod. $2011 ; 26 ; 235-44$.

13. Ben-Chetrit E, Backenroth R, Haimov-Kochman R, Pizov G. Azoospermia in familial Mediterranean fever patients: the role of colchicine and amyloidosis. Ann Rheum Dis. 1998;57:259-260.

14. Meseguer M, Garrido N, Remohí J, Pellicer A, Simón C, Martínez-Jabaloyas JM, et al. Testicular sperm extraction (TESE) and ICSI in patients with permanent azoospermia after chemotherapy. Human Reprod. 2003;18:12811285.

15. Anónimo. Subgrupos ATC y Principios activos de mayor consumo en el Sistema Nacional de Salud en 2010. Información terapéutica del Sistema Nacional de Salud. 2010;34:89-93.

16. MacGilchrist AJ, Howden CW, Kenyon CJ, Beastall GH, Reid JL. The effects of omeprazole on endocrine function in man. Eur J Clin Pharmacol. 1987;32:423-425.

17. Dammann HG, Bethke T, Burkhar- dt F, Wolf N, Khail H, Luehmann R. Effects of pantoprazole on endocrine function in healthy male volunteers. Aliment Pharmacol Ther. 1994;8:549554.

18. Dammann HG, von zur Mühlen A, Balks HJ, Damaschke A, Steinhoff J, Hennig U, et al. The effects of lansoprazole, 30 or $60 \mathrm{mg}$ daily on intragastric $\mathrm{pH}$ and on endocrine function in healthy volunteers. Aliment Pharmacol Ther. 1993;7:191-196.

19. Adler ID, Schmid TE, Baumgartner A. Induction of aneuploidy in male mouse germ cells detected by the spermFISH assay: a review of the present database. Mutat Res. 2002;504:173182.

20. Ratnasooriva WD, Jayakody JR. Long-term administration of large doses of paracetamol impairs the reproductive competence of male rats. Asian J Androl. 2000;2:247-255.

21. Jaqueson A, Semont H, Thevenin M, Warnet JM, Prost R, Claude JR. Effect of daily high doses of paracetamol given orally during spermatogenesis in the rat testes. Arch Toxicol. 1984;7:164-166.

22. Laxminaravana D, Murthy DK, Subramanyam S. Cytogenetical action of paracetamol on meiotic cells of male mice. Cytobios. 1980;27:27-34.

23. Knuth UA, Kühne J, Crosby J, BalsPratsch M, Kelly RW, Nieschlag E. Indomethacin and oxaprozin lower seminal prostaglandin levels but do not influence sperm motion characteristics and serum hormones of young healthy men in a placebo-controlled double-blind trial. J Androl. 1989;10:108-119.

24. Fuse H, Minagawa H, Ito H, Shimazaki J. The effects of prostaglandin synthetase inhibitor on male infertility. Hinyokika Kiyo. 1984;30:1439-1445.

25. Freiza R, Roselló Catafu J, Gelpí E, Iglesias Cortit JL, Ballescá JL, de Paz JL, et al. Comparative study of anti-inflammatory drugs and sulphasalazine in relation to prostaglandin $\mathrm{E}$ and 19hydroxylated prostaglandin E levels and human male fertility. Prostaglandins Leukot Med. 1984;16:359369.

26. Niederberger C. Atorvastatin and male infertility: is there a link?. J Androl. 2005;26:12.

27. Hildebrand RD, Hepperlen TW. Lovastatin and hypospermia. Ann Intern Med. 1990;112:549-550.

28. Jay RH, Sturley RH, Stirling C, McGarrigle HH, Katz M, Reckless JP, et al. Effects of pravastatin and cholestyramine on gonadal and adrenal steroid production in familial hypercholesterolaemia. Br J Clin Pharmacol. 1991;32:417-422.

29. Bernini GP, Brogi G, Argenio GF, 
Moretti A, Salvetti A. Effects of long-term pravastatin treatment on spermatogenesis and on adrenal and testicular steroidogenesis in male hypercholesterolemic patients. J Endocrinol Invest. 1998;21:310-317.

30. Michel MC. Alpha1-adrenoceptors and ejaculatory function. Br J Pharmacol. 2007;152:289-290.

31. Gregoriou 0, Vitoratos N, Papadias C, Gargaropoulos A, Konidaris S, Giannopoulos V, et al. Treatment of idiopathic oligozoospermia with an alfa-blocker: a placebo-controlled double-blind trial. Int J Fertil Womens Med. 1997;42:301-305.

32. Hellstrom WJ, Sikka SC. Effects of alfuzosin and tamsulosin on sperm parameters in healthy men: results of a short-term, randomized, double-blind, placebo-controlled, crossover study. J Androl. 2009;30:469-474.

33. Koyuncu H, Serefoglu EC, Yencilek E, Atalay H, Akbas NB, Sarica K. Escitalopram treatment for premature ejaculation has a negative effect on semen parameters. Int $\mathrm{J}$ Impot Res. 2011;23:257-261.

34. Tanrikut C, Feldman AS, Altemus M, Paduch DA, Schlegel PN. Adverse effect of paroxetine on sperm. Fertil Steril. 2010;94:1021-1026.

35. Akasheh G, Sirati L, Noshad Kamran AR, Sepehrmanesh Z. Comparison of the effect of sertraline with behavioral therapy on semen parameters in men with primary premature ejaculation. Urology. 2014;83:800-804.
36. Attia SM, Bakheet SA. Citalopram at the recommended human doses after long-term treatment genotoxic for male germ cell. Food Chem Toxicol. 2013;53:281-285.

37. Safarinejad MR. Sperm DNA damage and semen quality impairment after treatment with selective serotonin reuptake inhibitors detected using semen analysis and sperm chromatin structure assay. J Urol. 2008;180:2124-2128.

38. Xiaotian X, Hengzhong Z, Yao X, Zhipan Z, Daoliang X. Effects of antiepileptic drugs on reproductive endocrine function, sexual function and sperm parameters in Chinese Han men with epilepsy. J Clin Neurosci. 2013;20:1492-1497.

39. Rauchenzauner M, Bitsche G, Svalheim S, Tauboll E, Haberlandt E, Wildt L, et al. Effects of levetiracetam and valproic acid monotherapy on sex-steroid hormones in prepuberal children-results from a pilot study. Epilepsy Res. 2010;88:264-268.

40. Beytur A, Ciftci 0, Oguz F, Oguzturk H, Yilmaz F. Montelukast attenuates side effects of cisplatin including testicular, spermatological, and hormonal damage in male rats. Cancer Chemother Pharmacol. 2012;69:207-213.

41. Xu B. Remifentanil impairs sperm motility reversibly in vitro. J Biocherm Mol Toxicol. 2012;26:176-177.

42. $\mathrm{Xu} \mathrm{B}$, Wang $\mathrm{YJ}$, Wang $\mathrm{ZP}, \mathrm{Hu} \mathrm{YP}$, Wang XH, Li Q. Effects of remifentanil combined with naloxone on hu- man sperm motility. Zhonghua Nan Ke Xue. 2011;17:926-929.

43. Konarzewska B, Wolczynski S, Szulc A, Galinska B, Poplawska R, Waszkiewicz N. Effect of risperidone and olanzapine on reproductive hormones, psychopathology and sexual functioning in male patients with schizophrenia. Psychoneuroendocrinology. 2009;34:129-139.

44. Tsuboi T, Bies RR, Suzuki T, Mamo DC, Pollock BG, Graff-Guerrero A, et al. Hyperprolactinemia and estimated dopamine D2 receptor occupancy in patients with schizophrenia: analysis of the CATIE data. Prog Neuropsychopharmacol Biol Psychiatry. 2013;45:178-182.

45. Geller B, Luby JL, Joshi P, Wagner $\mathrm{KD}$, Emslie G, Walkup JT, et al. A randomized controlled trial of risperidone, lithium, or divalproex sodium for initial treatment of bipolar I disorder, manic or mixed phase, in children and adolescents. Arch Gen Psychiatry. 2012;69:515-528.

46. De Siqueira Ringel S, de Amorim Júnior AA, Amorim MJ, Brito LT, Morais RN, de Torres SM, et al. Endocrine and testicular changes induced by olanzapine in adult Wistar rats. J Appl Toxicol. 2013;33:24-31.

47. Mortimer D, Barrat CL, Björndahl L, de Jager C, Jequier AM, Muller CH. What should it take to describe a substance or product as "sperm-safe”. Hum Reprod Update. 2013;19:145. 